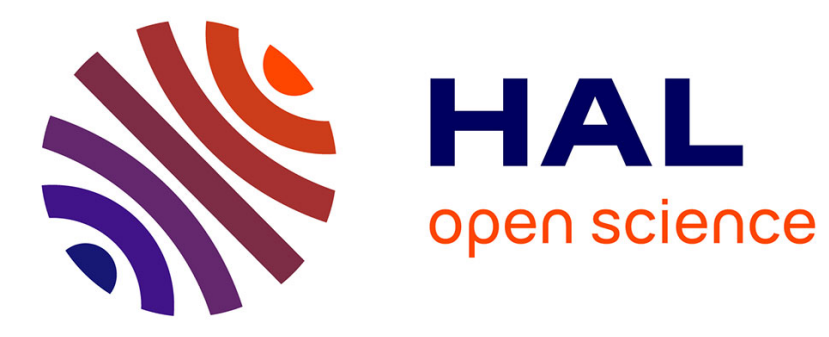

\title{
Converging Data Storytelling and Visualisation Yangjinbo Zhang
}

\section{To cite this version:}

Yangjinbo Zhang. Converging Data Storytelling and Visualisation. Esteban Clua; Licinio Roque; Artur Lugmayr; Pauliina Tuomi. 17th International Conference on Entertainment Computing (ICEC), Sep 2018, Poznan, Poland. Springer International Publishing, Lecture Notes in Computer Science, LNCS-11112, pp.310-316, 2018, Entertainment Computing - ICEC 2018. 10.1007/978-3-319-994260_36. hal-02128586

\section{HAL Id: hal-02128586 \\ https://hal.inria.fr/hal-02128586}

Submitted on 14 May 2019

HAL is a multi-disciplinary open access archive for the deposit and dissemination of scientific research documents, whether they are published or not. The documents may come from teaching and research institutions in France or abroad, or from public or private research centers.
L'archive ouverte pluridisciplinaire HAL, est destinée au dépôt et à la diffusion de documents scientifiques de niveau recherche, publiés ou non, émanant des établissements d'enseignement et de recherche français ou étrangers, des laboratoires publics ou privés. 


\title{
Converging Data Storytelling and Visualisation
}

\author{
Yangjinbo Zhang ${ }^{1}$ \\ ${ }^{1}$ Visualisation and Interactive Media Lab. (VisLab.) \\ Curtin University, Perth, WA, AUSTRALIA, http://curtin.edu/vismedia \\ yangjinbo. zhangepostgrad. curtin.edu.au
}

\begin{abstract}
.
The goal of this paper is to discuss and review existing literature in the field of data storytelling and draw the relationship between data storytelling and visualisation. It also associates both domains, as well as it explores pathways how to better present and deliver data driven presentations. To associate data storytelling with visualisation will be a worth-studying and intriguing direction. We summarize in a brief discussion the convergence between visualisation and data storytelling by pinpointing to key theories, illustrating the potentia, and present both concepts as tool in data science, aesthetics and information visualisation.
\end{abstract}

Keywords: Data Storytelling, Serious Storytelling, Visualisation, Data visualisation, Narrative Structure, Story, Media Study, New Media, Cognition.

\section{$1 \quad$ Introduction}

The role of data in today's world is clear. With the increasing amounts of data, it's getting more and more important to find adequate ways to communicate, present, and make data understandable to individuals. Story telling has played a role as "message carrier" in human history for a very long time. In comparison with raw data - a narration is a more natural and smooth-understanding form of message. The convergence of both concepts - storytelling and data science - seems to be the next natural next step forward, in making data easier to comprehend, and to communicate.

Def. Visualization (Tufte 1983): According to (Tufte 1983), visualisation is visually present measured quantities with visual elements such as lines, shapes, colors, words, symbols and so on. It is the art and tool for reasoning data and information (Tufte 1983).

Def. Narrative (Chatman 1978): According to Chatman's idea (Chatman 1978), narrative is a whole with nature of both transformation (deliverable and expressable) and self-regulation (self-maintained and closed structure) and is constructed with discrete events and existents, and with a sequential composition, that function as a whole (Chatman 1978).

Def. Data Storytelling (Knaflic 2015): according to Knafilc's idea (Knaflic 2015), data itself is difficult to understand, but there are stories in data bringing it to life that allow 
to communicate data in a much more efficient way. Data storytelling transforms data into a better form that can support decision making (Knaflic 2015).

In the way of exploration of how to better present and deliver data, how to make the process more vivid, convenient and plentiful. Within this paper, we discuss the multidisciplinary facet of data storytelling, and it's basic theories.

\section{Review of Basic Theories}

A brief review of the relevant topics and literatures are shown as below (see Table 1).

Table 1. Overview of Literature Resources

\begin{tabular}{|c|c|c|c|}
\hline Topic & Description & Aspects & Ref. \\
\hline \multicolumn{4}{|c|}{ Visualisation } \\
\hline Data-ink & $\begin{array}{l}\text { Cord of an image that cannot be erased, and } \\
\text { Maximizing data-ink, and minimizing non } \\
\text { data-ink improves efficiency }\end{array}$ & $\begin{array}{l}\text { Efficiency of } \\
\text { visualisation }\end{array}$ & (Tufte 1990) \\
\hline $\begin{array}{l}\text { Analysis and } \\
\text { presentation } \\
\text { of data }\end{array}$ & $\begin{array}{l}\text { Design principles fundamental to human } \\
\text { cognition and motivation, closely related to } \\
\text { some basic human activities }\end{array}$ & $\begin{array}{l}\text { Visualisation } \\
\text { principles }\end{array}$ & (Tufte 2006) \\
\hline $\begin{array}{l}\text { Visual } \\
\text { cognition }\end{array}$ & $\begin{array}{l}\text { Research in aspects such as the working } \\
\text { memory/long-term memory, knowledge for- } \\
\text { mation and transfer, visual cognitive system } \\
\text { and visual thinking processes }\end{array}$ & $\begin{array}{l}\text { Visualisation } \\
\text { and cogni- } \\
\text { tion }\end{array}$ & (Ware 2013) \\
\hline $\begin{array}{l}\text { Visualisation } \\
\text { design }\end{array}$ & $\begin{array}{l}\text { Ingredients of good visualisation form the } \\
\text { perspective of designer, reader and data }\end{array}$ & $\begin{array}{l}\text { Design of } \\
\text { visualisation }\end{array}$ & $\begin{array}{l}\text { (Iliinsky and } \\
\text { Steele 2010, } \\
\text { 2011) }\end{array}$ \\
\hline $\begin{array}{l}\text { Cognitive } \\
\text { Big Data }\end{array}$ & $\begin{array}{l}\text { Framework for cognitive understanding of } \\
\text { data, and categorizing the traits of Big Data } \\
\text { as in }\end{array}$ & $\begin{array}{l}\text { Psychologi- } \\
\text { cal frame- } \\
\text { work }\end{array}$ & $\begin{array}{l}\text { (Lugmayr et } \\
\text { al. 2016, } \\
2017 \mathrm{~b})\end{array}$ \\
\hline \multicolumn{4}{|c|}{ Data Storytelling } \\
\hline $\begin{array}{l}\text { Storytelling } \\
\text { with data }\end{array}$ & $\begin{array}{l}\text { Guidelines for the use of storytelling in data } \\
\text { presentation, and support cognition and de- } \\
\text { cision-making }\end{array}$ & $\begin{array}{l}\text { Data presen- } \\
\text { tation }\end{array}$ & (Knaflic 2015) \\
\hline $\begin{array}{l}\text { Serious } \\
\text { storytelling }\end{array}$ & $\begin{array}{l}\text { Story for serious purposes. How storytelling } \\
\text { can be used for non-entertaining purposes, } \\
\text { such as support decision-making and share } \\
\text { knowledge. }\end{array}$ & Serious story & $\begin{array}{l}\text { (Lugmayr et } \\
\text { al. 2017c) }\end{array}$ \\
\hline \multicolumn{4}{|c|}{ Information Aesthetics } \\
\hline $\begin{array}{l}\text { Information } \\
\text { aesthetics }\end{array}$ & $\begin{array}{l}\text { It provides a unique thread to combine sci- } \\
\text { ence and art. Research includes studies of } \\
\text { sematic and aesthetic information and uncer- } \\
\text { tainties in perceptions of symbols. }\end{array}$ & $\begin{array}{l}\text { Information } \\
\text { study }\end{array}$ & (Moles 1968) \\
\hline \multicolumn{4}{|c|}{ Aesthetics Theory } \\
\hline $\begin{array}{l}\text { Aesthetic } \\
\text { response } \\
\text { theory }\end{array}$ & $\begin{array}{l}\text { Art can neither be fully identical with the } \\
\text { work created by author, nor with the realisa- } \\
\text { tion by the viewer. It exists halfway between } \\
\text { these two poles. }\end{array}$ & $\begin{array}{l}\text { Aesthetic re- } \\
\text { sponse }\end{array}$ & (Iser 1978) \\
\hline $\begin{array}{l}\text { Layered } \\
\text { structure of } \\
\text { art }\end{array}$ & $\begin{array}{l}\text { Inner structure of art, phonetic formation, } \\
\text { units of meaning, schematized aspects and } \\
\text { represented objectives. }\end{array}$ & $\begin{array}{l}\text { Structure of } \\
\text { art }\end{array}$ & $\begin{array}{l}\text { (Ingarden } \\
1973 \mathrm{a} ; \mathrm{b})\end{array}$ \\
\hline
\end{tabular}




\begin{tabular}{llll}
\hline Story Narration & & & \\
\hline $\begin{array}{l}\text { Narrative } \\
\text { structure }\end{array}$ & $\begin{array}{l}\text { Narrative parts and subfactors affecting nar- } \\
\text { ration: the story (depicted in a narrative); } \\
\text { discourse (depiction of narrative) }\end{array}$ & $\begin{array}{l}\text { Structure of } \\
\text { story }\end{array}$ & $\begin{array}{l}\text { (Chatman } \\
1978)\end{array}$ \\
\hline $\begin{array}{l}\text { Characteristics } \\
\text { of storytelling }\end{array}$ & $\begin{array}{l}\text { Tell-ability of a story, characteristics of } \\
\text { good storytelling and storytelling tech- } \\
\text { niques. }\end{array}$ & $\begin{array}{l}\text { Storytelling } \\
\text { techniques }\end{array}$ & $\begin{array}{l}\text { (Baker and } \\
\text { Greene 1977) }\end{array}$ \\
\hline Media Studies & & & \\
\hline $\begin{array}{l}\text { Medium's affect } \\
\text { to message }\end{array}$ & $\begin{array}{l}\text { Content of a media is always another media, } \\
\text { media as translator and carrier of infor- } \\
\text { mation }\end{array}$ & $\begin{array}{l}\text { Nature of } \\
\text { media }\end{array}$ & $\begin{array}{l}\text { (McLuhan } \\
\text { 1964) }\end{array}$ \\
\hline $\begin{array}{l}\text { Charateristics of } \\
\text { new media }\end{array}$ & $\begin{array}{l}\text { Numerical representation, modularity, auto- } \\
\text { mation, viability, and transcoding }\end{array}$ & $\begin{array}{l}\text { Media char- } \\
\text { acteristics }\end{array}$ & $\begin{array}{l}\text { (Manovich } \\
\text { 2001) }\end{array}$ \\
\hline
\end{tabular}

\subsection{Visualisation}

In recent researches, visualisation as a research domain has considerably developed. There are a lot of important ideas and concepts being provided in many aspects. On visual efficiency, Tufte (Tufte 1983, 1990) contributed an important concept: data-ink. Data-ink is the cord of an image that cannot be erased. If it is, the message will be incomplete. Maximising data-ink and minimising non-data-ink can dramatically improve efficiency (Tufte 1990). Tufte also cited efficiency as only one of the dimensions of visual design. Other dimensions include complexity, structure, density and beauty (Tufte 2006). So comprehensively consider the various dimensions of visualisation design will be a necessary way to improve the overall quality.

The principles of data analysis and presentation (Tufte 2006), are about the design principles are based on the fundamentals of human cognition and motivation. These are closely related to some basic human activities: decision, purpose, response, consequence, planning, and so on (Tufte 2006). It will be important to further understand and conduct a more comprehensive analysis of what aspects and elements are essential to create human centered visualizations, as e.g. discussed in (Lugmayr et al. 2016, 2017b). Research around visual cognition (Ware 2013), addresses aspects such as the working memory/long-term memory, knowledge formation/transfer, visual cognitive systems and visual thinking processes. Different frameworks have been researched, as well as a concept of sensory versus arbitrary symbols has been provided (Ware 2013).This concept provides a good guide to analyse the relationship between visual cognition and graphic symbolic elements. A important work in visualisation cognition and its information visualization cognition framework has been provided by (Patterson et al. 2014).

\subsection{Storytelling and Narrative Structure}

The purpose of visualisation is to translate a message into visual form for more convenience understanding. And in order to achieve even better understanding, the massage should be re-organised and re-edited before it is visualised. In the domain of storytelling, there are some theories and researches which can support for this.

According to Chatman's narrative structure research, narratives have two major parts: the story - which is depicted in a narrative - and the discourse - how a narrative is depicted. The story part has two subtopics: events (actions, happenings) and existents 
(characters, setting). Many subfactors also affect narration (Chatman 1978). He sees story as a form of sharing massages has been tested by throughout centuries as a way of exchanging information easily to understand, and attractive for people. Therefore, the most obvious step is to link data with storytelling to make data understandable.

How to naturally combine the cord data into story units, meanwhile remain the clarity of the cord data. This is the aim and the direction. About how a story is present in the aspect of visual, Chatman also provided some guide in his research of visual space in cinematic narrative (Chatman 1978) and its digital production (Lugmayr et al. 2008). Visual factors such as scale, density, texture, position, colour, angle, size are the key elements that are presenting and telling the story in the aspect of sense of visual (Chatman 1978). In fact, this is sharing very similar principle with visualisation, and helps it's creation process.

In the research of characteristics of storytelling (Baker and Greene 1977), a central question is discussed: what makes a story tellable? Some of the characteristics are: a single and clear theme, dramatic appeal, characterization (Baker and Greene 1977). This provide a direction which is worth to think, when a message is reorganized and reedited into a story, how this story should like in order to being attractive and can catch people's attention. To explore how these characteristic elements fit in the context of data visualisation, will definitely help to improve the overall quality of cognition and understanding.

In terms of narratives in specific media, research into linguistic structure of comic narratives (Cohn 2014) also provide valuable ideas. In this research, it reveals three structures which are affecting in the visual aspect of comic. They are graphic structure, narrative structure and external composition structure. Through graphic structure, lines and shapes combine into image. Then with narrative structure, a series of images organise into a coherent message. Last with external composition structure, all the organised images fit into a specific media space. We also have to consider the 'medium' carrying the story - which we explore in the next section of the paper.

\subsection{Media and Communication Studies}

The media is not only the carrier of the information, but also part of the information. It affects how information is presented. "The medium is the message" as stated by McLuhan (McLuhan 1964). McLuhan's research also revealed that the content of a media is always another media. In fact, media plays the role of translator; it carries the information from one form into another form. When discussing the media, some very important parts will be the characteristic of medias, difference between medias, which aspects of message are being affected by the forms of media, and when in the translating form media to another media which parts of message will be changed because of the affection by different media forms. Manovich's research (Manovich 2001) into new media reveals that - compared to former media - new media in the digital age have many new characteristics. These are e.g. (Manovich 2001): numerical representation, modularity, automation, variability and transcoding. These affect how information is 
presented in new media. Today, media study theories extend towards smart media environments (Pogorelc et al. 2012) and (Lugmayr et al. 2009) and topics like personalization (Uhlmann and Lugmayr 2008).

\subsection{Data Storytelling}

In the field of data storytelling, there are many important contributions have been made. Knaflic (Knaflic 2015), provides a method to associate live narration with data figures. This combination provides a good idea to understand the application and context of data story telling. This research also provides a guideline to guide the use of storytelling to better present data and support cognition and decision-making (Knaflic 2015).

Recent research in this domain has produced valuable concepts such as e.g. serious storytelling and cognitive big data (Lugmayr et al. 2017a; c). Questions like the difference between serious storytelling and entertaining storytelling are addressed. It also rethinks, if some methods and theories of traditional storytelling can support serious storytelling; and which domains or disciplines should be considered. These concepts are vital how data storytelling supporst cognition and human activities.

\section{Discussion and Conclusion}

Data storytelling and digital visualisation are relatively young concepts. To develop data storytelling, it is essential to intersect theories from multiple domains and disciplines. It is necessary to discuss and analyze which theories in each domains contribute to data storytelling. It will also require creative methods to create these (Lugmayr 2011). It is necessary to essential to explore different characteristics in different aspects and domains and distill the required ones to develop data storytelling as a discipline. In this paper, some key-theories contributing to data storytelling are explored and keyliterature described. These need to be applied in concrete application scenarios and application domains to allow new insights into data and decrease the cognitive load of individuals exploring different aspects in data. This research paper is research in progress and is only a starting point for further investigation.

\section{References}

Baker A, Greene E (1977) Storytelling : art and technique. Bowker, New York

Chatman SB (1978) Story and discourse : narrative structure in fiction and film. Cornell University Press, Ithaca, N.Y

Iliinsky N, Steele J (2011) Designing Data Visualizations : Representing Informational Relationships. O'Reilly Media, Incorporated, Sebastopol, UNITED STATES

Iliinsky N, Steele J (2010) Beautiful Visualization: Looking at Data through the Eyes of Experts. O'Reilly Media, Incorporated, Sebastopol, UNITED STATES

Ingarden R (1973a) The cognition of the literary work of art. Northwestern University Press, Evanston

Ingarden R (1973b) The literary work of art. Northwestern University Press, Evanston 
Iser W (1978) The act of reading: a theory of aesthetic response. Johns Hopkins University Press, Baltimore

Knaflic CN (2015) Storytelling with Data: A Data Visualization Guide for Business Professionals. Wiley

Lugmayr A (2011) Applying "Design Thinking” As a Method for Teaching in Media Education. In: Proceedings of the 15th International Academic MindTrek Conference: Envisioning Future Media Environments. ACM, New York, NY, USA, pp 332-334 http://doi.acm.org/10.1145/2181037.2181100

Lugmayr A, Adrian H, Golebiowski P, et al (2008) E = MC2+ 1: a fully digital, collaborative, high-definition (HD) production from scene to screen. Computers in Entertainment 6:1-33

Lugmayr A, Risse T, Stockleben B, et al (2009) Special issue on semantic ambient media experiences. Multimedia Tools and Applications 44:331-335

Lugmayr A, Stockleben B, Scheib C, et al (2016) A Comprehensive Survey on Big Data Research and It's Implications - What is really 'new' in Big Data? It's Cognitive Big Data. In: Ting-Peng Liang S-IC Shin-Yuan Hung Patrick Y.K. Chau (ed) Proceedings of the 20th Pacific-Asian Conference on Information Systems (PACIS 2016). http://www.pacis2016.org/abstract/Index

Lugmayr A, Stockleben B, Scheib C, Mailaparampil M (2017a) Cognitive big data: survey and review on big data research and its implications. What is really "new" in big data? Journal of Knowledge Management 21:197-212

Lugmayr A, Stockleben B, Scheib C, Mailaparampil M (2017b) Cognitive Big Data. Survey and Review on Big Data Research and its Implications: What is Really "New"? Cognitive Big Data! Journal of Knowledge Management (JMM) 21: http://www.emeraldgrouppublishing.com/products/journals/call_for_papers.htm?id $=5855 \mathrm{k}$, Journal of Knowledge Management $/$ Emerald

Lugmayr A, Sutinen E, Suhonen J, et al (2017c) Serious storytelling - a first definition and review. Multimedia Tools and Applications 76:15707-15733

Manovich L (2001). MIT Press, Cambridge, Mass.

McLuhan M (1964) Understanding media : the extensions of man. Routledge \& Kegan Paul Limited, London

Moles AA (1968) Information theory and esthetic perception. Univ. of Illinois Press, Urbana

Patterson RE, Blaha LM, Grinstein GG, et al (2014) A human cognition framework for information visualization. Computers \& Graphics 42:42-58

Pogorelc B, Vatavu R-D, Lugmayr A, et al (2012) Semantic ambient media: From ambient advertising to ambient-assisted living. Multimedia Tools and Applications 58:399-425. doi: 10.1007/s11042-011-0917-8

Tufte ER (1983) The visual display of quantitative information. Graphics Press, Cheshire, Conn.

Tufte ER (1990) Data-Ink Maximization and Graphical Design. Oikos 58:130-144

Tufte ER (2006) Beautiful evidence. Graphics Press, Cheshire, Conn.

Uhlmann S, Lugmayr A (2008) Personalization algorithms for portable personality. In: Proceedings of the 12th international conference on Entertainment and media in the ubiquitous era. ACM, Tampere, Finland

Ware C (2013) Information visualization: perception for design, 3rd edition. Elsevier/MK, Amsterdam ; Boston 